\title{
Lexikala analyser av muntlig, tangentbordsskriven och dikterad text producerad av barn med stavningssvårigheter
}

\author{
Sanna Kraft ${ }^{\star 1}$, Fredrik Thurfjell ${ }^{1}$, John Rack $^{2}$ och Åsa Wengelin ${ }^{1}$ \\ ${ }^{1}$ Göteborgs universitet och ${ }^{2}$ Linnéuniversitetet
}

\begin{abstract}
Abstrakt
För barn med stavningssvårigheter är skriftspråkande en stor utmaning och behovet att hitta nya redskap för att understödja deras skriftspråksutveckling är därför stort.

Att skriva med taligenkänning, diktering, skulle kunna underlätta skrivprocessen eftersom dikteringsverktyget reducerar kraven på skribenten att stava själv, och detta skulle därmed kunna frigöra kognitiva resurser till annan textbearbetning. Att diktera text innebär emellertid inte med nödvändighet en enklare textproduktion; dels behöver texten följa skriftspråksnormer trots att den produceras muntligt, dels behöver skribenten hitta strategier för att hantera tillfällen när verktyget inte uppfattar talet korrekt.

I föreliggande studie undersöks text producerad av barn med stavningssvårigheter. Lexikala egenskaper, textlängd och stavfel studeras i muntlig, skriven och dikterad text. Analyserna visar att de dikterade texterna innehåller färre stavfel än de skrivna samt att både skriven och dikterad text har högre lexikal densitet och högre andel långa ord jämfört med muntlig text. Detta antyder att deltagarna klarar att diktera texter med skriftspråkliga egenskaper. Däremot skiljde sig dikterad text varken från muntlig eller skriven text gällande textlängd eller lexikal diversitet.

Vår slutsats är att dikteringsverktyg kan användas för att underlätta skrivprocessen för barn med stavningssvårigheter, men det behövs vidare forskning som studerar hur olika undergrupper producerar text med dikteringsverktyg.
\end{abstract}

\section{Nyckelord: Skrivande; taligenkänning; läs- och skrivsvårigheter; mellanstadieelever}

\begin{abstract}
Lexical analyses of oral, typed and dictated text produced by children with spelling difficulties

For children with reading and writing difficulties, writing, in general, and spelling, in particular, is a significant challenge. Writing with speech recognition (dictation) can facilitate the writing process since the dictation tool removes the need to spell, freeing resources for other processes. Dictating, however, may not always provide a solution, since written text should follow the conventions of written language, even when produced orally. In addition, writers need strategies if the tool does not recognize the spoken words.
\end{abstract}

\footnotetext{
^Korrespondens: Sanna Kraft, Göteborgs universitet, Box 200, 40530 Göteborg. Epost: sanna. kraft@svenska.gu.se
} 
In the present study, children with spelling difficulties produced keyboard-written and dictated texts, and an oral account. The analyses showed that dictated texts, as expected, contained fewer spelling errors than keyboard-written texts, and that both of these had a higher lexical density than the oral accounts. This suggests that students are able to dictate using written language conventions. However, the dictated texts did not differ from the oral and keyboard-written texts in terms of length of text and proportion of long words. Our conclusion is that the dictation tool can be used to facilitate the children's writing process, but further research is needed to see if training in the use of the tool would bring more substantial benefits.

Keywords: Writing; speech-to-text; reading and writing difficulties; 10-12-year-olds

Responsible editor: Victoria Johansson

Received: April, 2019; Accepted: November, 2019; Published: December, 2019

\section{Inledning}

Att kunna uttrycka sig i skrift blir allt viktigare, såväl för att delta i demokratiska processer och klara arbetslivet som för att kunna vara delaktig i sociala sammanhang online. Att studera barns skrivande är därför av stor vikt, och det finns en rik elevtextforskning i Sverige. Exempel på områden som undersökts är högstadieelevers skriftspråksutveckling (t.ex. Nordenfors, 2011), textbedömning (Skar, 2013) och skrivundervisning (t.ex. Wirdenäs \& Holmberg, 2010). Den huvudsakliga ansatsen i dessa studier har varit sociokulturell och studierna har ofta fokuserat på högstadieoch gymnasieelever.

Däremot är forskningen om yngre elevers skrivande begränsad (se dock Bergh Nestlog, 2009) och forskning om skrivande hos mellanstadieelever med läs- och skrivsvårigheter i svensk kontext är i princip obefintlig. Hatcher, Snowling och Griffiths (2002) visar att det enligt både lärare och elever är produktion av skriven text, snarare än läsning, som utgör den största utmaningen för elever med läs- och skrivsvårigheter och eleverna lyfter särskilt svårigheter med att strukturera texten och visa sin kunskap genom text. Det eleverna beskriver som en utmaning är textgenereringen, själva skrivandet, och en förklaringsmodell till varför det är utmanande återfinns i "The Simple View of Writing" (Berninger et al., 2002) där skrivutveckling förklaras utifrån en triangelmodell över användningen av kognitiva resurser under skrivande. I basen finns transkribering, där stavning ingår, och exekutiv funktion, där revidering av text ingår. I toppen finns textgenereringen. Där ingår exempelvis att komma på idéer, göra ordval, använda sin bakgrundskunskap och relatera texten till uppgift och läsare (Berninger \& Amtmann, 2003). Textgenereringen är beroende av hur automatiserade förmågorna i basen av triangeln är. En skribent med stavningssvårigheter har således svårigheter med transkribering, som är en lågnivåprocess. Vid skrivande upptar denna process en stor del av den kognitiva kapaciteten vilket därmed begränsar arbete med textgenerering på en högre nivå (Berninger, Nielsen, Abbott, Wijsman \& Raskind, 2008). Detta kan i sin tur påverka textens längd och kvalitet (Limpo \& Alves, 2013; Wengelin, Johansson \& Johansson, 2014). Många studier bekräftar "The 


\section{S. Kraft, F. Thurfjell, F. Rack, och A. Wengelin}

simple View of Writing", och har visat att man genom att stödja processerna på en lägre nivå, som exempelvis att träna stavning (Berninger et al., 2002) eller strategier (Graham, Gillespie \& McKeown, 2013) kan frigöra utrymme för att arbeta med texten på en högre nivå.

Tidigare forskning visar att stavningssvårigheter tenderar att vara ett kvarvarande problem för elever med läs- och skrivsvårigheter, även om en fungerande läsförmåga har tränats upp (Berninger, 2006). Ett förslag som både pedagoger och forskare fört fram (MacArthur, 2009) är att taligenkänning, alltså att diktera text som datorn skriver, skulle kunna underlätta deras skrivprocess. Tanken är att det skulle kunna omfördela kognitiva resurser från lågnivåprocessen stavning till högnivåprocesser.

Att diktera innebär att producera skriven text i muntlig modalitet. Olika modaliteter ställer emellertid olika krav på språkproduktionen och det är inte nödvändigtvis lättare att diktera än att skriva med tangentbord. För att det ska fungera bra att diktera behöver man kunna hålla en lagom lång ordräcka i minnet och tala tydligt. Vidare krävs att man kan upptäcka och hantera när verktyget skriver fel, vilket ställer stora krav på läsförmågan. Slutligen behöver skribenten ha en medvetenhet om att det är skriven text som produceras och förhålla sig till skriftspråkliga konventioner, trots att texten produceras i muntlig modalitet. Därför är det relevant att undersöka i vilken utsträckning dikterade texter innehåller talspråkliga respektive skriftspråkliga drag.

De skillnader som tidigare visats vara mest framträdande mellan tal- och skriftspråk är lexikala skillnader, som skillnader i lexikal diversitet, alltså andel olika ord i relation till totalt antal ord, och densitet, alltså andel informationsbärande ord i relation till totalt antal ord (se t.ex. Chafe \& Tannen, 1987). Jämförelser av lexikala drag i dikterade texter med desamma i skriftlig och muntlig (i fortsättningen kallad muntlig text) språkproduktion kan därför bidra med kunskaper om huruvida taligenkänningsverktyg kan fungera som skrivverktyg för elever med läs- och skrivsvårigheter.

Det bör poängteras att barn med läs- och skrivsvårigheter är en heterogen grupp och förmågan att skriva innefattar betydligt fler förmågor än att stava, som till exempel generell språkförmåga, ordförråd och texterfarenhet (se till exempel Dockrell, 2009). I föreliggande studie, som är en inledande studie i ett större projekt om att skriva med taligenkänning, fokuserar vi på barn med stavningssvårigheter. Vi jämför texter de producerat muntligt med texter de dikterat och texter de skrivit med tangentbord för att se huruvida verktyget kan användas för att producera skriven text.

\section{Tidigare forskning}

Att producera skriven text är, som nämndes ovan, svårt för barn med läs- och skrivsvårigheter. Tidigare studier har visat att barn som har svårt med skriftproduktion har större svårigheter med stavning än med läsning (Berninger et al., 2002), och att stava 
är dessutom mer komplext än att läsa (Dockrell, 2009). Dessa svårigheter får konsekvenser för texten, och tidigare internationell forskning på barn i mellanstadieåldern med läs- och skrivsvårigheter har bland annat visat att deras texter har lägre lexikal diversitet och kvalitet (Sumner, Connelly \& Barnett, 2016; Berninger et al., 2008) jämfört med jämnåriga.

Den svenska skollag som trädde i kraft 2019 (SFS 2018:1098) poängterar att stöd ska ges till de elever som inte annars når målen, men forskning om hur stödet bör utformas saknas. Detta påpekas även i SBU-rapporten Dyslexi hos barn och unga tester och insatser (SBU, 2014), varför det är betydelsefullt att utreda vilket stöd som fungerar. Vidare bör man ha i åtanke att de nationella bedömningar som är baserade på skrift, med egentligt syfte att pröva elevers förmåga att resonera, riskerar att istället bedöma elevernas förmåga till skrivprocesser på lägre nivå, som att avkoda och stava (Berninger, 2006). Skolverket betonar att den förmåga som ska bedömas bör vara vägledande för att avgöra vilket stöd eleven behöver (Skolverket, 2018).

\section{Skriva med taligenkänning}

Endast ett fåtal tidigare studier, och inga svenska, har undersökt diktering som skrivverktyg. Haug och Klein (2018) jämförde hur diktering respektive handskrift fungerade tillsammans med skrivstrategiundervisning för 10-11-åringar utan svårigheter. Undervisningen hade god effekt på textkvalitet, textlängd och argumentation för båda skrivsätten. Diktering var alltså inte ett sämre skrivsätt för barn utan svårigheter. MacArthur och Cavalier (2004) undersökte hur gymnasieelever med och utan inlärningssvårigheter skrev i tre olika situationer: för hand, med diktering via taligenkänning samt med diktering till en person som skrev ned texten. Inga skillnader syntes gällande lexikala egenskaper och textlängd. För gruppen med svårigheter, men inte kontrollgruppen, bedömdes textkvaliteten vara högre för dikterade texter än handskrivna, särskilt för texter som dikterades till en person. Notera dock att studien genomfördes för över ett decennium sedan; dikteringsverktygen har utvecklats avsevärt sedan dess. En pilotstudie (Wengelin, Bengtsson \& Kraft, 2015) med mellanstadieelever utan svårigheter fann däremot högre lexikal diversitet $\mathrm{i}$ texter skrivna med tangentbord än texter dikterade till en person, vilket antyder en viss talspråklighet hos de dikterade texterna (jfr Chafe \& Tannen, 1987). Möjligen är det svårare att producera språk enligt skriftspråkliga normer när man dikterar. Eventuellt blir texter dikterade till en person, till skillnad från till ett verktyg, mer talspråkliga, även om MacArthur och Cavalier (2004) inte såg några skillnader i lexikala mått. Quinlan (2004) visade att 11-14-åriga barn med svårigheter dikterade längre texter jämfört med när de skrev för hand, däremot syntes inga skillnader i (holistiskt bedömd) kvalitet. Higgins och Raskind (1995) jämförde hur vuxna personer med svårigheter skrev utan stöd, dikterade till en person som skrev ned texten och dikterade med taligenkänning. Även de fann en viss fördel för diktering: de dikterade texterna innehöll fler långa ord och deltagarna uppgav själva att de inte behövde byta ut långa, svårstavade ord till korta, lättstavade när de dikterade. Med undantag för Quinlan har alltså de 


\section{S. Kraft, F. Thurfjell, f. Rack, och A․ Wengelin}

flesta studierna av diktering för personer med svårigheter fokuserat på äldre elever $\mathrm{i}$ engelskspråkiga kontexter och handskrift. Forskning som jämför diktering med att skriva med tangentbord hos mellanstadieelever med stavningssvårigheter saknas. Att undersöka detta i en svensk kontext kan ge betydelsefulla pedagogiska implikationer. Eftersom digitaliseringen går snabbt och barn i dag är mer vana vid datorer och lärplattor jämfört med för några år sedan, och eftersom dikteringsverktygen också utvecklats avsevärt, behövs nya studier om diktering (Perelmutter, McGregor \& Gordon, 2017).

\section{Tal och skrift}

Diktering kan beskrivas som en hybridform mellan tal och skrift eftersom produkten blir skriven text medan processen sker i muntlig modalitet. Som nämnts tidigare finns det stora skillnader mellan tal och skrift avseende lexikala aspekter, men talspråkets påverkan på texten när den dikteras är oklar. Därför är det av relevans att undersöka de skillnader som påvisats mellan tal och skrift även i dikterad text.

Tal och skrift produceras typiskt under skilda förutsättningar. I talsituationen har talaren mottagaren nära. Samtalet produceras i ett samarbete där deiktiska uttryck kan användas för att referera till objekt, parallellt med att parterna kan ge och få återkoppling. Skriftsituationen skiljer sig markant från talsituationen och kräver mer informationsbärande ord för att bli begriplig; den lexikala densiteten blir större. Skrift kan också kräva mer specifika och explicita beskrivningar än tal, vilket påverkar den lexikala diversiteten. Dessa skillnader har betonats av Chafe och Tannen (1987). Biber (1986) visade emellertid att genre kan ha större betydelse än modalitet, men varken han eller Chafe och Tannen undersökte detta hos samma personer.Yu (2009) analyserade däremot samma individer, men i olika genrer. Yu fann ingen skillnad mellan muntlig och skriven text, men kontrollerade inte för genre. För att veta vad man jämför behöver man dels ha kontroll över vilken genre som produceras, dels jämföra detta hos samma individer.

Några få studier har analyserat skillnader mellan muntlig och skriven text $\mathrm{i}$ samma genre hos samma individer. Som en del av ett större internationellt projekt (Berman \& Verhoeven, 2002) jämförde Johansson (2009) lexikal diversitet och densitet i muntlig och skriven text i utredande och narrativ text hos svenska elever i fyra olika åldersgrupper: 10-åringar, 13-åringar, 17-åringar och universitetsstudenter. Resultaten visade genomgående skillnader mellan muntlig och skriven text gällande både lexikal diversitet och densitet hos samtliga åldersgrupper, oberoende av genre.

Ännu färre studier har undersökt lexikala skillnader i olika modaliteter hos personer med läs- och skrivsvårigheter. Sumner, Connelly och Barnett (2016) visade att barn utan svårigheter hade högre lexikal diversitet i skriven text medan barn med svårigheter hade högre i muntlig. Wengelin (2007) visade att vuxna utan svårigheter hade högre lexikal diversitet $\mathrm{i}$ skriven jämfört med muntlig text och deras muntliga text hade samma nivå av lexikal diversitet som såväl skriven som muntlig text 
producerad av vuxna med svårigheter; de skrev mer som de talade. Detta kan möjligen stödjas av att lexikal diversitet i en del studier har visat sig korrelera med textkvalitet (t.ex. Olinghouse \& Leaird, 2009). Sådana resultat bör tolkas med försiktighet eftersom vissa genrer kräver högre lexikal diversitet och andra inte (Skar \& Berge, 2017). Hög lexikal diversitet kan alltså inte jämställas med hög kvalitet i alla genrer. I den här studien använder vi likartade skrivuppgifter för att så långt som möjligt endast jämföra modalitet.

\section{Syfte}

Syftet med studien är att undersöka om, och i så fall hur, dikterade texters lexikala egenskaper skiljer sig från a) tangentbordsskriven och b) muntlig text inom individer med stavningssvårigheter. Baserat på tidigare forskning är en möjlig prediktion att diktering skulle kunna underlätta skrivandet genom att omfördela kognitiva resurser från stavningsfokus till formulering och textgenerering. Därför analyserar vi lexikala variabler såsom lexikal diversitet, lexikal densitet och andel långa ord. $\mathrm{Om}$ skrivandet faktiskt underlättas av diktering borde texterna också kunna bli längre, varför vi även undersöker textlängd. Möjligen är det svårt att i muntlig modalitet producera text som följer skriftspråkliga normer och de dikterade texterna skulle därför kunna ha drag av muntlig text i form av lägre lexikal densitet och diversitet. Taligenkänningssystem är dessutom inte perfekta. Ibland skriver verktyget inte det som sägs, vilket kan påverka de lexikala måtten. Om deltagarna upptäcker sådana fel kan det vara lättast att skriva ordet med tangentbordet. Då kan stavfel uppkomma, varför även stavfel analyseras. Vi förväntar oss att såväl lexikal diversitet och densitet som textlängd ska vara högre vid diktering än i tangentbordsskriven respektive muntlig text.

En viktig faktor är emellertid att den individuella variationen inom gruppen med stavningssvårigheter, gällande exempelvis lexikal förmåga, arbetsminne och uttal, kan påverka resultaten och det är inte självklart att diktering fungerar för alla. I denna första studie undersöker vi i vilken utsträckning dikteringsverktyg kan påverka texters lexikala egenskaper hos elever med stavningssvårigheter, oavsett andra svårigheter. Detta undersöker vi eftersom tidigare studier (se ovan) har visat att personer med läs- och skrivsvårigheter, i vid bemärkelse, ofta skriver med lägre lexikal diversitet och densitet. Gruppens heterogenitet utgör en begränsning i hur resultaten kan tolkas och vi har valt att inte jämföra texternas kvalitet i det här skedet.

\section{Frågeställningar}

- Hur skiljer sig dikterad text från muntlig och tangentbordsskriven gällande de lexikala måtten lexikal diversitet, lexikal densitet och andel långa ord hos elever med stavningssvårigheter?

- Hur skiljer sig texterna åt gällande textlängd och stavfel? 


\section{Metod}

\section{Deltagare}

Arton deltagare med stavningssvårigheter, 9 pojkar och 9 flickor, 10;0-13;0 år $(M=11 ; 56)$, rekryterades via specialpedagog och klasslärare i sex skolor i mindre städer i södra Sverige. Även deltagare utan svårigheter rekryterades, men i denna artikel analyseras endast texter av deltagarna med stavningssvårigheter. Studien är kvantitativ och har en inom-gruppdesign; texter från varje elev jämförs i tre olika modaliteter. När deltagarna hade fyllt i en intresseanmälan kontaktades vårdnadshavare och såväl de som eleverna gav skriftligt samtycke. Deltagarna informerades om att de när som helst kunde avbryta sin medverkan. Studien har etikprövats. ${ }^{1}$

\section{Inklusions- och exklusionskriterium}

Forskning om skrivning är, i förhållande till läsning, mycket bristfällig (Berninger, Nielsen \& Abbott, 2008) och i denna studie är skrivsvårigheter i fokus. Eftersom "barn med dyslexi" är en heterogen grupp (Dockrell, 2009) och det i Sverige inte råder konsensus om hur dyslexidiagnos ställs (SBU, 2014) valde vi att inte använda dyslexidiagnos som inklusionskriterium. Inte heller läsförmåga eller språklig förmåga utgjorde inklusionskriterium. Vi inkluderade de som presterade lika med eller under stanine $3^{2}$ på det normerade stavningstestet Rättstavning 2 ur DLS (Järpsten \& Taube, 2010). Gruppens medelvärde på stavningstestet var stanine $1.89(S D=0.76)$. Denna grupp är emellertid också heterogen (Dockrell, 2009) och för att ge en transparent bild av gruppen rapporterar vi resultat över avkodning och språkförståelse - även om dessa inte analyseras vidare. Som kunde förväntas var deltagarnas resultat för avkodning, mätt med avkodningstestet LäSt (Elwér, Fridolfsson, Samuelsson \& Wiklund, 2011) låga; gruppen som helhet presterade under genomsnittet jämfört med barn i samma ålder. ${ }^{3}$ För semantisk och grammatisk förståelse däremot var gruppens resultat som helhet genomsnittliga. ${ }^{4,5}$

\footnotetext{
${ }^{1}$ Dnr. $702-17$.

${ }^{2}$ STANINE $=$ STAndardised NINE grade scale. Skalan omvandlar resultat på ett standardiserat test till en niogradig skala där 1 är lägst och 9 högst, baserat på testets normalfördelningskurva. Värden under 4 indikerar svårigheter.

${ }^{3}$ Avkodning prövades med deltest ur LäSt. Resultatet på testet omvandlas till ett percentilvärde mellan 1-99, baserat på testets normalfördelningskurva. Värden under 30 indikerar svårigheter. Gruppens resultat för Avkodning nonord var $(M=25.0, S D=17.49)$ och för Avkodning ord $(M=23.89, S D=17.37)$.

${ }^{4}$ Semantisk förståelse prövades med Likheter 2 ur CELF (Wiig, Wayne \& Semel, 2003). Resultatet på testet omvandlas till skalpoäng, baserat på testets normalfördelningskurva, där 1 är lägst och 19 högst. Värden under 8 indikerar svårigheter $(M=9.22, S D=3.23)$.

${ }^{5}$ Grammatisk förståelse prövades med Trog 2 (Bishop, 2009). Testet ger ett percentilvärde. Gruppens resultat $\operatorname{var}(M=48.33, S D=21.8)$.
} 
Generellt exklusionskriterium var diagnosticerad utvecklingsstörning eller autismspektrumstörning. Flerspråkiga elever inkluderades om de hade gått hela sin skolgång i Sverige, och därmed fått sin läs- och skrivundervisning på svenska.

\section{Materialinsamling}

Deltagarna träffade förstaförfattaren enskilt 3-4 timmar uppdelat på två till fyra tillfällen. Då genomfördes ett större testbatteri där bland annat arbetsminneskapacitet, läsförmåga, språkförmåga och tangentbordsskicklighet undersöktes. Hur förmågorna relaterar till deras skrivande kommer att analyseras i en senare studie. Därutöver producerade deltagarna muntlig, skriven och dikterad text. I föreliggande studie analyseras endast stavningstestet och texterna i de tre modaliteterna.

Texterna eliciterades med korta filmsnuttar som presenterade moraliska dilemman: fusk och stöld. Filmklippen hämtades från ett längre filmklipp som har använts i forskning om tal- och skrivutveckling tidigare (Berman \& Verhoeven, 2002). Vi lät deltagarna producera utredande texter där de redogjorde för hur de trodde att en superhjälte skulle resonera utifrån filmen. Den muntliga uppgiften genomfördes initialt, eftersom tidigare forskning visat att man tenderar att ta med sig drag från skriftlig text till muntlig om denna produceras först i större utsträckning än det omvända (Strömqvist, 2008). Därefter genomfördes antingen den dikterade eller skriftliga texten, enligt ett slumpningsschema. Deltagarna informerades om att de hade en halvtimme på sig och att de skulle skriva i minst 15 minuter.

Produktionen av de muntliga texterna filmades med en Apple Ipad. De skriftliga texterna producerades på en Macbook med integrerat tangentbord i tangentloggningsprogrammet ScriptLog (Frid, Johansson, Johansson \& Wengelin, 2014). Tangentloggning registrerar alla tangentnedslag och musrörelser och möjliggör därmed analys av skrivprocessen i realtid. I ScriptLog möjliggörs ingen hjälp med stavning, stor bokstav eller dylikt. De dikterade texterna producerades i Microsoft Word med stavningshjälpen avstängd och skärm- och ljudinspelades med Camtasia (TechSmith, 2018).

\section{Introduktion till dikteringsverktygsverktyget}

Innan deltagarna dikterade på egen hand fick de se en fem minuter lång film om hur dikteringsverktyget fungerar och därefter fick de en kort genomgång av verktyget. De fick diktera en övningsuppgift genom att beskriva hur deras rum såg ut samt diktera ett antal förutbestämda meningar. Förstaförfattaren och deltagaren gick gemensamt igenom dels hur taligenkänningens felskrivningar kunde redigeras, dels hur man kunde göra både röststyrda redigeringar och redigeringar med mus och tangentbord.

\section{Analys}

Som antyddes i frågeställningarna analyserade vi såväl texternas lexikala egenskaper (lexikal diversitet, lexikal densitet och andel långa ord) som textlängd och stavning. 


\section{S. Kraft, F. Thurfjell, Ұ. Rack, och A. Wengelin}

\section{Beräkning av lexikala mått}

Det finns inget ultimat mått för att mäta lexikal diversitet (Šišková, 2012), men VocD är ett mått som ofta förespråkas (McCarthy \& Jarvis, 2010). I denna studie beräknades lexikal diversitet med hjälp av VocD i CLAN (MacWhinney, 2014). I princip alla mått bygger i grunden på en beräkning av typer i relation till förekomster men det finns olika sätt att kompensera för variation i textlängd (McCarthy \& Jarvis, 2010). VocD beräknas genom att 35-50 slumpvis valda ord i texten jämförs med varandra, vilket upprepas tre gånger och därefter genereras ett medelvärde. Det innebär att värdet kan skilja sig något från gång till gång men stickprovet från texterna är alltid lika stort. Måttet kräver emellertid en textlängd på minst 50 ord. Olyckligtvis bestod fyra av de skrivna, tre av de dikterade och en muntlig text av färre än 50 ord och därmed kunde VocD inte beräknas för dessa texter. Därför genomfördes också beräkningar med hjälp av OVIX ${ }^{6}$ för materialets samtliga texter. OVIX beräknades via "Lix.se" och är ett vanligt förekommande mått inom nordisk textforskning. Måttet tar större hänsyn till textens längd än en enkel typ-/förekomstberäkning, men kompenserar eventuellt sämre för textlängd än VocD. Vi återkommer till detta i diskussionen. Även textlängd och andel långa ord ${ }^{7}$ togs fram via "Lix.se". Lexikal densitet beräknades genom att en frekvenslista över deltagarnas samtliga texters ord skapades i AntConc (Anthony, 2018). Dessa ordklasstaggades i SPARV (Borin m.fl., 2016) och kategoriserades efter studiens kriterier för stängda och öppna ordklasser: verb, substantiv, adjektiv och adverb avledda från adjektiv klassades som öppna, resterande som stängda. Detta följer den definition som ges i Johansson (2009) och Wengelin (2002). Listan korrigerades manuellt. Utifrån denna lista skapades två korpusar över materialets öppna och stängda ord. I AntWordProfiler (Anthony, 2012) kördes varje deltagares respektive text mot korpusen för öppna ord för att räkna ut hur stor andel av orden som hörde till denna korpus. Stavfel beräknades genom att skrivna och dikterade texter rättades manuellt med Microsoft Words spåra ändringar-funktion. Som stavfel räknades ord som inte finns med i Svenska Akademiens ordlista. Exempelvis räknades supperhjelte 'superhjälte' som ett felstavat ord och två antal stavfel. Felskrivningar som tydligt var tangentbordsmissar (intilliggande tangenter, exempelvis der istället för det) räknades inte in. Andel stavfel beräknades genom att dela antal felstavade ord med antal ord i texten.

\section{Bearbetning av texter inför lexikal analys}

För att kunna genomföra tillförlitliga lexikala analyser av texterna i de olika modaliteterna krävdes viss korrigering av desamma. Som utgångspunkt användes de slutgiltiga produkterna av texterna i de olika modaliteterna. För de muntliga texterna

\footnotetext{
${ }^{6}$ OVIX räknas ut genom att dela antalet unika ord med resultatet av 2 minus antalet ord delat med antalet unika ord: $\log$ (tokens) $/ \log (2-(\log$ (types) $/ \log$ (tokens) vilket tar bättre hänsyn till textens längd än TTR. Beskrivningen är hämtad från "Lix.se".

${ }^{7}$ Ord med fler än sex bokstäver. Måttet utgår ifrån Björnssons (1968) frekvensberäkningar av ordförekomst på svenska.
} 
innebär det att hela processen, inklusive omformuleringar och omstarter, räknats in, medan dessa normalt inte förekommer i de skrivna och dikterade texternas slutversion. Just eftersom muntliga och skriftliga texter produceras under olika villkor skiljer sig slutprodukterna och det är dessa skillnader som studien avser jämföra för att se om muntliga drag finns i de dikterade texterna.

De muntliga texterna transkriberades i CLAN (MacWhinney, 2014). Tvekljud exkluderades. För att lexikal diversitet och densitet skulle kunna beräknas korrekt korrigerades stavfel och tangentbordsmissar i de tangentbordsskrivna texterna. Felaktiga val av de/dem korrigerades, då det skulle kunna påverka den lexikala diversiteten, dom lämnades okorrigerade, liksom preteritumändelser eller andra grammatiska fel.

De dikterade texterna korrigerades i två steg. I ett första steg analyserade vi texten som den faktiskt blev och som den därmed skulle ha sett ut om den blev inlämnad i en skolsituation. Här inkluderades därför fel som uppkom genom att verktyget skrev något annat än skribenten sa och som lämnats orättade. Stavfel korrigerades i enlighet med de skrivna texterna. I steg 2 intresserade vi oss för skribenternas faktiska kompetens att producera språk, som det skulle ha blivit om verktyget hade fungerat felfritt. I detta steg korrigerade vi de felskrivningar som åstadkommits av verktyget. Detta möjliggjordes eftersom processen ljud- och skärminspelades och vi därmed hade tillgång till deltagarens hela dikteringsprocess. Vissa av deltagarna hade svårt att upptäcka verktygets felskrivningar, då det kräver genomläsning av texten. Detta resulterade $\mathrm{i}$ att många felaktiga ord lämnades kvar i texten. I ett fall blev så många sådana fel kvarlämnade att texten blev omöjlig att läsa utan att ta hjälp av skärminspelningen, se Exempel 1a och 1b. I Exempel 1a är enbart stavfel korrigerade och i $1 \mathrm{~b}$ har även verktygets felskrivningar korrigerats.

\section{Exempel 1 a-Dikterad text där enbart stavfel har korrigerats}

Tappar $500 \mathrm{kr}$

Det handlar om en tjej som tal upp sin mobil och tappar $500 \mathrm{kr}$.

Sen kommer det en tjej och cigarr att den andra tjejen tappa detta hon tar upp det och Sprang iväg med fem hundralappar

Sen Kommer min kvart från himlen stopp spelreglerna tillbaka den hon säger nej han säger jo anmäler jag dig.

Anmäl inte mig.

Ok jag lämnat tillbaka den imorgon

Jag kommer hålla på imorgon om du inte lämna tillbaka den så!!

Vad då!

Du vill inte veta ...

Nästa dag kom hon framträngande filerna tillbaka [...].

\section{Exempel $1 b$ - Dikterad text där taligenkänningens felskrivningar har korrigerats}

Tappar $500 \mathrm{kr}$

Det handlar om en tjej som tar upp sin mobil och tappar $500 \mathrm{kr}$. 
Sen kommer det en tjej och ser att den andra tjejen tappa detta hon tar upp det och Sprang iväg med femhundralappen

Sen Kommer det en människa från himlen och säger stopp ska du inte lämna tillbaka den hon

säger nej han säger jo anmäler jag dig.

Anmäl inte mig.

Ok jag lämnar tillbaka den imorgon

Jag kommer kolla på dig imorgon om du inte lämnar tillbaka den så!!

Vad då!

Du vill inte veta ...

Nästa dag kom hon fram till den andra tjejen och lämnade tillbaka [...].

I Exempel 1a ser vi ord som cigarr, spelreglerna, framträngande och filerna, vilka skribenten aldrig sagt. Redigering, och därmed läsning, blir en viktig del av skrivprocessen när deltagarna dikterar text och vi redovisar därför resultaten i samma steg som vi korrigerat texterna. Den första versionen kallas dikterad text och den andra versionen dikterad korrigerad text.

\section{Statistiska beräkningar}

I studien jämförs texter i tre olika modaliteter hos en och samma skribent, och dessa jämförelser beräknas på gruppnivå. Eftersom datamängden var liten och inte genomgående normalfördelad använde vi det icke-parametriska Friedmans test för jämförelser mellan modaliteter. Samtliga data i materialet var kvotdata. Beräkningarna genomfördes i R (2017) och konfidensintervallet var 95\%. När Friedmans test visade en signifikant skillnad mellan modaliteterna genomfördes post-hoc-analyser med det icke-parametriska Wilcoxon Sign Rank Test för beroende ${ }^{8}$ data. Samtliga signifikanta resultat kvarstod efter Holms korrektion för upprepade analyser.

\section{Resultat}

Deltagarnas resultat på de olika variablerna presenteras uppdelat på modalitet $\mathrm{i}$ Tabell 1. Inledningsvis redovisas de lexikala beräkningarna i de olika modaliteterna, vilket relaterar till vår första forskningsfråga och därefter presenteras resultaten för textlängd och stavfel, vilket relaterar till vår andra forskningsfråga. Icke-signifikanta resultat redovisas i fotnot, för att underlätta läsningen.

Friedmans test visade inga signifikanta skillnader i modalitet för lexikal diversitet oavsett om VocD eller OVIX analyserades. ${ }^{9}$ Detta betyder att deltagarnas texter hade liknande lexikal diversitet i samtliga modaliteter. För att visuellt synliggöra

\footnotetext{
${ }^{8}$ Datan i materialet är beroende, eftersom samma deltagare har producerat texter i de olika modaliteterna till skillnad från om vi hade haft tre grupper - en för varje modalitet.

${ }^{9}$ För VocD var resultatet $\chi^{2}=(2, n=18)=3.1667, p=.2053$ när dikterad text analyserades och $\chi^{2}=$ $(2, n=18)=1.2727, p=.5292$ när dikterad korrigerad text analyserades. För OVIX var resultatet $\chi^{2}=$ $(2, n=18)=4.7778, p=.09173$, respektive $\chi^{2}=(2, n=18)=4.3529, p=.1134$.
} 
Lexikala analyser av muntlig, tangentbordsskriven och dikterad text




skillnaderna i de olika måtten på gruppnivå, se Figur 1 där spridningsmåtten för lexikal diversitet i respektive modalitet mätt med VocD och OVIX presenteras i två separata boxdiagram.
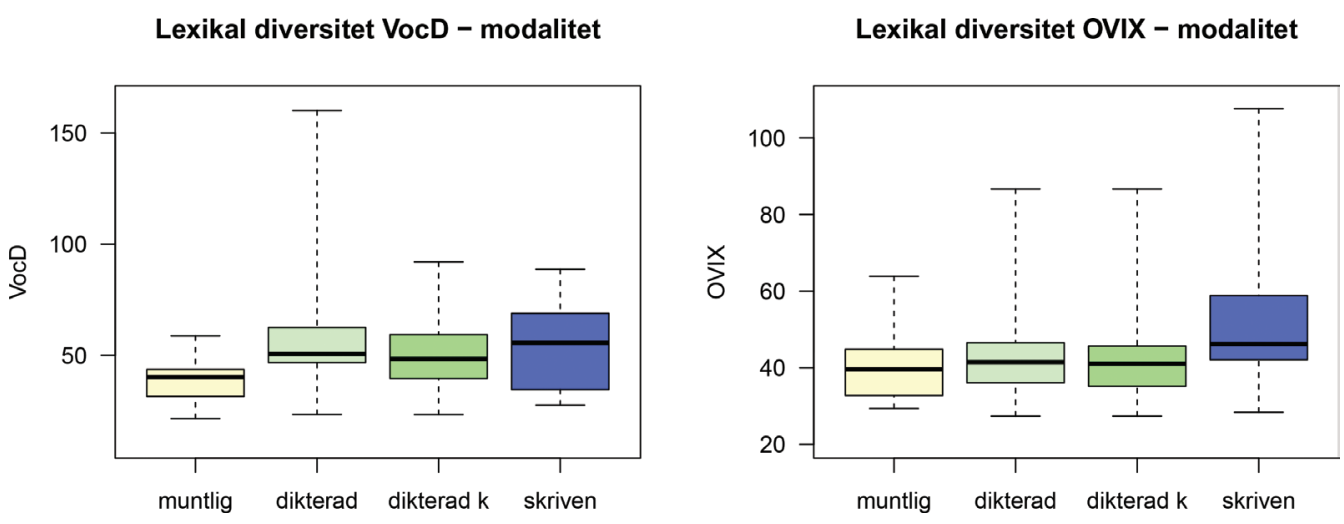

Figur 1. Lexikal diversitet (VocD och OVIX) för respektive modalitet. Dikterad står för dikterad text där enbart stavfel blivit rättade, Dikterad $k$ står för den dikterade texten där verktygets felskrivningar korrigerats till vad deltagaren sa. Den övre kanten av boxen visar den 75 :e percentilen $(75 \%$ av deltagarna har ett värde $\leq$ denna nivå), strecket i boxen visar medianen $(50 \%$ av deltagarna har ett värde under och $50 \%$ över denna nivå) och den undre kanten den 25 :e percentilen ( $25 \%$ av deltagarna har ett värde $\leq$ denna nivå).

Notera att spridningen i VocD skiljer sig för den dikterade texten som inte har korrigerats för verktygets felskrivningar (VocD dikterad). Här ingår ord som deltagaren inte haft för avsikt att skriva, som felaktigt producerats av dikteringsverktyget, och som deltagaren inte korrigerat. Här syntes ord som exempelvis cigarr, vilket inte hörde ihop med texten i övrigt. Att måttet har högst värde där dessa ord ingår antyder att ämnet för uppgiften kan ha begränsat deltagarnas ordval och därmed den lexikala diversiteten. Korrelationsberäkningar, med Spearman Rank Correlation, mellan OVIX och VocD visade dock en stark korrelation $(>0.8)$ i samtliga modaliteter.

Till skillnad från beräkningarna för lexikal diversitet uppvisades signifikanta skillnader för lexikal densitet. Friedmans test visade en signifikant skillnad mellan modaliteterna både när dikterad, $\chi^{2}=(2, n=18)=18.778, p<.001$, och dikterad korrigerad, $\chi^{2}=(2, n=18)=17.294, p<.001$, text användes. Post-hoc-analyser visade att skillnader fanns mellan muntlig och skriven text, $p<.001$, muntlig och dikterad text, $p<.001$, och muntlig och dikterad korrigerad text, $p<.001$. Som framgår i Tabell 1 är medianvärdena för dikterad text något högre än för skriven, men inga signifikanta skillnader uppmättes mellan skriven och dikterad, $p=.56$, respektive mellan skriven och dikterad korrigerad, $p=.38$. Se Figur 2 för en visuell presentation över spridningsmåtten för lexikal densitet i de olika modaliteterna $\mathrm{i}$ ett boxdiagram. 


\section{Lexikal densitet - modalitet}

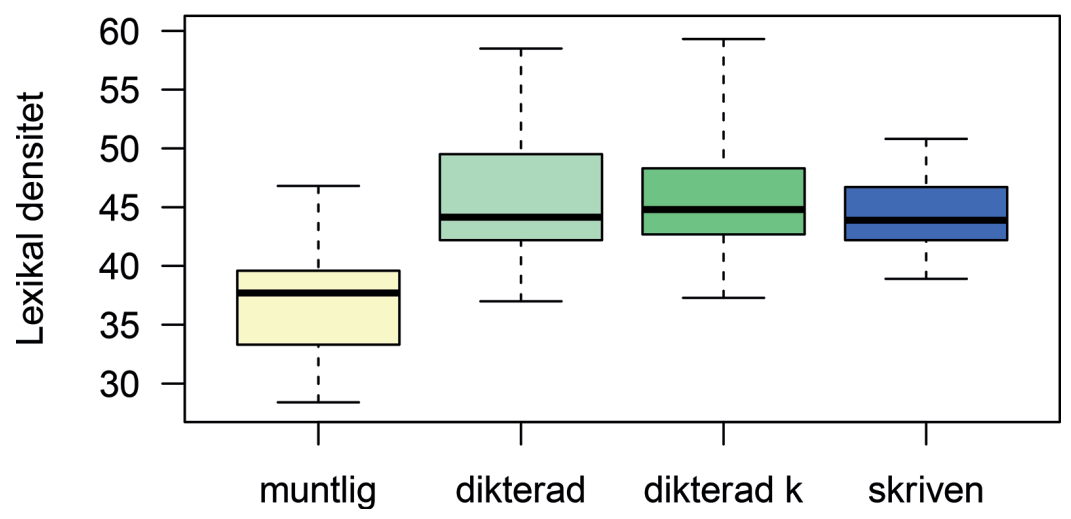

Figur 2. Lexikal densitet för respektive modalitet.

Deltagarnas muntliga texter innehöll således fler funktionsord och färre informationsbärande ord än både deras dikterade och skrivna texter.

Friedmans test visade även en signifikant skillnad $\mathrm{i}$ andel långa ord mellan modaliteterna, både när dikterad, $\chi^{2}=(2, n=18)=8.7042, p=.013$, och dikterad korrigerad text, $\chi^{2}=(2, n=18)=11.313, p=.0035$, analyserades. Post-hoc-test visade att skillnader fanns mellan muntlig och skriven text, $p=.002$, muntlig och dikterad, $p=.008$, och muntlig och dikterad korrigerad, $p=.004$. Ingen skillnad uppmättes mellan skriven och dikterad text, $p=.65$ respektive $p=.80$.

Vi fann inga signifikanta skillnader mellan modaliteterna gällande textlängd ${ }^{10}$, och spridningen i textlängd var stor.

Andel och antal stavfel var, som förväntat, signifikant lägre i dikterad jämfört med skriven text, $p<.001$.

\section{Diskussion}

I föreliggande studie analyserar vi text producerad av samma deltagare i olika modaliteter. Både skriv- och dikteringsprocessen är komplex och kräver ett samspel mellan olika kognitiva förmågor. Som nämndes tidigare är det en begränsning i studien att vi inte kan urskilja hur olika förmågor, såsom arbetsminne och språklig förmåga, gynnar eller missgynnar de olika skrivsätten. Däremot kan studiens resultat ge en fingervisning om hur diktering påverkar texters lexikala egenskaper för barn med stavningssvårigheter som grupp. För att få större insikt i för vem diktering som verktyg är användbart vore det relevant att dels göra jämförelser med en kontrollgrupp,

${ }^{10}$ Resultatet var $\chi^{2}=(2, n=18)=2.1111, p=.348$ när dikterad text ingick i analysen, och $\chi^{2}=$ $(2, n=18)=3.2941, p=.1926$ när dikterad korrigerad text analyserades. 


\section{S. Kraft, F. Thurfjell, J. Rack, och A․ Wengelin}

det vill säga hur barn utan svårigheter hanterar uppgiften, dels av hur skriv- och dikteringsprocessen ser ut hos olika undergrupper av barn med stavningssvårigheter.

Studiens frågeställningar diskuteras inledningsvis nedan. Först diskuteras textlängd och därefter de lexikala måtten i relation till modalitet. Sedan diskuteras andel stavfel i skriven och dikterad text. Därefter förs en metoddiskussion och slutligen ges en sammanfattande diskussion.

Att textlängden inte skiljde sig åt mellan skriven och dikterad text överensstämmer med MacArthurs och Cavaliers (2004) resultat men skiljer sig från Quinlans (2004). Vi förväntade oss att dikteringsverktyget skulle kunna frigöra kognitiva resurser åt deltagarna till att producera mer text. Resultatet kan ha sin förklaring i att deltagarna inte har kunnat dra nytta av verktyget utan träning i att använda det. Vidare antydde vi i inledningen att det fanns en risk att dikteringsverktyget skulle ta stor kognitiv kapacitet i anspråk samt att det inte är självklart att man utan vidare träning kan producera skrift i muntlig modalitet, men olyckligtvis har vi inget mått på hur krävande textproduktionen har varit för deltagarna. Hur automatisering av dikteringsverktyget hänger ihop med textlängd kommer vi undersöka närmare i en kommande interventionsstudie.

Andel långa ord skiljde sig såväl mellan muntlig och skriven som muntlig och dikterad text. Deltagarna har inte använt fler långa, svårstavade ord i sina dikterade texter jämfört med i sina skrivna, men alltså högre andel i båda dessa modaliteter jämfört med i muntlig modalitet. Detta resultat motsäger Higgins och Raskinds (1995) resultat för äldre personer och skulle kunna bero på att uppgiften i denna studie eventuellt begränsade vokabulären och inte lämnade stora möjligheter för deltagarna att använda längre ord i hög utsträckning. Det skulle också kunna bero på att användningen av dikteringsverktyget inte är automatiserad och därmed tar för stor kognitiv kapacitet i anspråk, vilket då inte ger stort utrymme till att ägna sig åt ordval. En annan möjlighet är att deltagarna ännu inte insett att de med dikteringsverktyget skulle kunna skriva längre ord enklare, vilket deltagarna i Higgins och Raskinds (1995) studie, med äldre deltagare, resonerade om som en fördel med diktering. Ytterligare en tanke är att elever med läs- och skrivsvårigheter har färre erfarenheter av text och därför ett mindre ordförråd, eftersom de tenderar att läsa och skriva i mindre utsträckning än jämnåriga (Stanovich, 1986). Vår studie betonar således vikten av att ytterligare studera anledningen till att andel långa ord inte skiljer sig mellan skriven och dikterad text.

Ett resultat som på många sätt hänger ihop med andel långa ord är lexikal densitet, eftersom långa, specificerande ord oftast hör till kategorin öppna ord. Att lexikal densitet i muntlig text skiljer sig från skriftlig ligger i linje med vad Johansson (2009) såg i barns texter. Resultatet skiljer sig dock från vad Wengelin (2007) såg hos vuxna med svårigheter, där lexikal densitet inte skiljde sig mellan muntlig och skriftlig produktion. I vår studie särskiljer sig alltså muntlig från skriven text, men att samma resultat skulle synas i dikterad text var inte självklart, eftersom risken fanns att deltagarna inte skulle kunna anpassa sig efter skriftspråkets normer under diktering. Resultaten i vår 
studie visar dock att deltagarna klarar att anpassa sig; den dikterade texten påminner mer om skriven än om muntlig text.

Studiens resultat gällande lexikal diversitet (hur många olika ord man använder) skiljer sig inte mellan modaliteterna. Resultatet skiljer sig från Johansson (2009), som påvisade dessa skillnader mellan tal och skrift hos barn utan svårigheter i samma ålder, men överensstämmer med Wengelin (2002) som inte såg dessa skillnader hos vuxna med läs- och skrivsvårigheter. Huruvida deltagarna har hög lexikal diversitet i muntlig text eller låg i dikterad och skriven går inte att avgöra utan en kontrollgrupp, men en jämförelse med Johansson (2009) visar att våra deltagares muntliga texter ligger nära medelvärdet för såväl 10- som 13-åringarna i Johanssons material, medan en större skillnad syns i skrift. En möjlig förklaring till utebliven signifikant skillnad mellan modaliteterna i föreliggande studie skulle kunna vara att deltagarna ännu inte kommit så långt i sin skriftspråksutveckling att de klarar att anpassa sina lexikala val till vad som krävs i skrift. En annan aspekt är att typ av skrivuppgift kan påverka hur kreativ man kan vara i sitt skrivande, vilket kan påverka textens lexikala diversitet (Skar \& Berge, 2017). Skar och Berge problematiserar även att alla genrer inte är lika beroende av ett varierat ordval. De undersökte OVIX och lärares bedömning i två texttyper, en föreställa sig-uppgift och en utforska-uppgift, och såg att OVIX korrelerade med textbedömning i föreställa sig-uppgiften men inte utforska-uppgiften. Eventuellt har föreliggande studies uppgift, som påminner om föreställa sig-uppgiften, varit för snäv och inte inbjudit deltagarna till att bygga ut sin text i hög utsträckning, eller så har eleverna ännu inte lärt sig hantera genrespecifika skrivsätt. Vidare har tidigare forskning visat att lexikal diversitet korrelerar med textlängd (Connelly m.fl., 2006) och i vår studie är spridningen i textlängd stor och texterna dessutom korta överlag, vilket kan ha påverkat den lexikala diversiteten (se t.ex. McCarthy \& Jarvis, 2010). Ytterligare en faktor som kan ha haft betydelse är att användningen av dikteringsverktyget ännu inte är automatiserad. Både vid diktering och skrivning tenderar deltagarna att jobba med texten på ordnivå, men troligen av olika anledningar. Att hitta och korrigera fel tar troligen mycket kognitiv kapacitet $i$ anspråk vid diktering, vilket tidigare lyfts av MacArthur (2009). Om deltagarna skulle kunna automatisera den lågnivåprocess som stavning innebär, genom att träna mer på att diktera, skulle de teoretiskt sett kunna använda mer kognitiva resurser till att exempelvis göra lexikala val och skriva längre.

Deltagarnas dikterade text innehöll, som väntat, signifikant färre stavfel än deras skrivna. Även om vi inte genomfört textkvalitetsbedömningar i studien, så visar tidigare forskning av exempelvis Graham, Harris och Hebert (2011) att en text med stavfel påverkar läsaren att bedöma texten som sämre jämfört med samma text utan stavfel. Resultatet påvisar därför en fördel med diktering. Men verktyget är inte perfekt; stavfel kan uppkomma när skribenten korrigerar ett fel genererat av verktyget. Att stavfel faktiskt syns i de dikterade texterna visar däremot att deltagarna granskar och reviderar sin text i viss utsträckning. 


\section{S. Kraft, F. Thurfjell, Ұ. Rack, och A. Wengelin}

\section{Metoddiskussion}

Då studiens deltagare är relativt få till antalet och variationen i måtten är stor, bör resultaten tolkas med viss försiktighet.Vidare visar våra resultat att vilket mått som väljs för att mäta lexikal diversitet har betydelse, och en medvetenhet kring detta behövs vid analys av texters lexikala egenskaper. Det är problematiskt att mäta lexikal diversitet i korta texter i allmänhet och av olika längd i synnerhet eftersom variationen av ord man använder sig av tenderar att minska allt eftersom texterna blir längre, vilket de olika måtten försöker kompensera för. Resultaten påVocD och OVIX skiljer sig i vår studie även om de korrelerar - och påverkas ofrånkomligt av textlängd. Texten i Exempel 3, som är den text i materialet som har högst värde för lexikal diversitet mätt med OVIX, illustrerar detta. Observera att utdraget är deltagarens hela text. VocD-resultaten får därför anses vara mer valida i den här studien.

\section{Exempel 3 - Skriven text}

Filmen hanlade om en pojke som fuskade.

Min super hjälte skulle inte bry sig om det.

I föreliggande studie jämförs måtten emellertid inte med en jämförelsegrupp; samma deltagares texter jämförs mellan modaliteter. För att närmare analysera hur den lexikala diversiteten varierar, dels med modalitet, dels med individuell förmåga, vore det önskvärt att jämföra resultaten såväl med en kontrollgrupp som i olika åldersgrupper, och i korta respektive långa texter. För att göra sådana systematiska jämförelser behöver deltagarantalet vara större.

Texternas längd kan ha påverkats av deltagarnas ålder. Åldersspridningen i studien var relativt stor och vi kunde se en tendens till att äldre elever i vår studie jämförelsevis skrev längre texter. Det är troligt att de äldre eleverna har mer erfarenhet av att skriva generellt och har fått jämförelsevis mer skrivundervisning och mer språklig exponering överlag. Vidare kan uppgiften ha påverkat kreativa aspekter av skrivandet och därmed den lexikala diversiteten. Däremot bör inte uppgiften ha påverkat texternas lexikala densitet i lika hög utsträckning, eftersom detta mått snarare är beroende av den kommunikativa situationen.

\section{Sammanfattande diskussion}

Att vi inte ser några signifikanta skillnader mellan dikterad och skriven text överlag visar att den dikterade texten blir lik deltagarnas skrivna text gällande de lexikala egenskaperna samt textlängd, vilket överensstämmer med MacArthur och Cavalier (2004). Detta tillsammans med att stavfel minskade signifikant i dikterad text styrker användning av diktering som skrivsätt för personer med stavningssvårigheter. Resultatet gällande lexikal diversitet motsäger eventuellt detta till viss del, eftersom såväl elevernas skrivna som dikterade text var lika deras muntliga motsvarighet för detta mått. Resultatet ligger i linje med vad Wengelin (2007) tidigare rapporterat 
hos vuxna med läs- och skrivsvårigheter. För att närmare utreda hur diktering påverkar textens lexikala diversitet vore det önskvärt att jämföra resultaten med en kontrollgrupp.

Noteras bör den stora spridning vi ser i de undersökta måtten; den individuella variationen är stor. Ytterligare forskning behövs för att utreda om undervisning av dikteringsverktyget och skrivstrategiundervisning kan utjämna denna variation, vilket även har efterfrågats av MacArthur och Cavalier (2004). Därtill behövs forskning som utreder hur individuella förmågor som arbetsminneskapacitet och språkförmåga påverkar såväl skriv- och dikteringsprocess som färdig text.

Avslutningsvis är det inte tillräckligt att erbjuda ett dikteringsverktyg och förvänta sig att tillämpningen sker intuitivt. Att diktera är, precis som konventionellt skrivande, komplext och innefattar flertalet kognitiva processer. Samspelet mellan dessa processer och hur de skiljer sig behöver undersökas vidare. En pedagogisk implikationen vår studie kan bidra med är att verktyget kan underlätta elevernas skrivande, men verktyget ensamt kan inte ge strategier för hur man skriver en bra text.Vikten av att kombinera undervisning $i$ en specifik förmåga (som stavning eller verktyg) med skrivstrategiundervisning har lyfts i forskning tidigare (Berninger m.fl., 2008). En kombination av diktering och skrivstrategiundervisning kan innebära fler möjligheter att underlätta och utveckla skrivförmågan hos elever med skrivsvårigheter, varför vi kommer undersöka detta i en framtida interventionsstudie.

\section{Tack}

Tack till såväl anonyma granskare som redaktörer, vars konstruktiva kommentarer har varit mycket värdefulla $i$ arbetet med artikeln. Tack även till Marcus och Amalia Wallenbergs Minnesfond för den finansiering som möjliggjort föreliggande studie.

\section{Forfatterbiografi}

Sanna Kraft är legitimerad logoped med examen från Göteborgs universitet. Hon har arbetat som skollogoped med handledning kring och utredning av språk-, läs- och skrivsvårigheter. Hon är doktorand på Institutionen för svenska språket på Humanistiska fakulteten vid Göteborgs universitet. Hennes forskningsintressen rör främst skrivprocesser och språkförmåga i relation till dessa. Av speciellt intresse är skrivande hos personer med språk-, läs- och skrivsvårigheter och verktyg för att underlätta deras skrivande.

Fredrik Thurfjell är legitimerad logoped och har länge arbetat med dyslexiutredningar av barn, ungdomar och vuxna. Nu verksam inom habiliteringen i Stockholm och är särskilt intresserad av kompenserande verktyg som underlättar läsning och skrivning i studier och vardagsliv.

John Rack är docent på Institutionen för pedagogik och lärande vid Linnéuniversitetet. Hans forskningsintressen innefattar teorier om läs- och skrivundervisning 
och utformning av kompensatoriska insatser för personer med behov av specialpedagogik, som exempelvis personer med dyslexi, samt utvärdering av dessa insatser. Han är också delägare och konsult till företaget Oribi som exempelvis utvecklar rättstavningsprogram.

Åsa Wengelin är professor på Institutionen för svenska språket och vicedekan för forskning på Humanistiska fakulteten vid Göteborgs universitet. Hennes forskningsintressen innefattar relationen mellan talat och skrivet språk, läs- och skrivprocesser, utvecklingsrelaterade och förvärvade läs- och skrivsvårigheter, läsbarhet samt verktyg för att underlätta skrivande. Hennes senast publicerade artiklar rör skrivprocesser samt internetanvändning och identitet hos personer med afasi.

\section{Referenser}

Anthony, L. (2012). AntWordProfiler. (Version 1.2.1m, Macintosh OX) [Programvara]. Tokyo, Japan: Waseda University. Tillgänglig på: https://www.laurenceanthony.net/software/antwordprofiler/.

Anthony, L. (2018). AntConc, (Version 3.5.6) [Programvara]. Tokyo, Japan: Waseda University. Tillgänglig på: https:/www.laurenceanthony.net/software/antwordprofiler/.

Bergh Nestlog, E. (2009). Perspektiv $i$ elevtexter: skriftligt argumenterande $i$ grundskolans mellanår. Doktorsavhandling, Växjö universitet, Institutionen för humaniora.

Berman, R., \& Verhoeven, L. (2002). Cross-linguistic perspectives on the development of text-production abilities: Speech and writing. Written Language E Literacy, 5(1), 1-43.

Berninger, V. W. (2006). A developmental approach to learning disabilities. I R. K. Ann \& I. E. Sigel, (Red.), Handbook of child psychology, vol. 4, Child Psychology in Practice, (s. 420-452). Wiley Online Library.

Berninger, V. W., Vaughan, K., Abbott, R. D., Begay, K., Coleman, K. B., Curtin, G., Hawkins, J. M., \& Graham, S. (2002). Teaching spelling and composition alone and together: Implications for the simple view of writing. Fournal of Educational Psychology, 94(2), 291-304.

Berninger,V.W., \& Amtmann, D. (2003). Preventing written expression disabilities through early and continuing assessment and intervention for handwriting and/or spelling problems: Research into practice. I H. L. Swanson, K. R. Harris, \& S. Graham (Red.), Handbook of learning disabilities (s. 345-363). New York: Guilford Press.

Berninger, V. W., Nielsen, K. H., Abbott, R. D., Wijsman, E., \& Raskind, W. (2008). Writing problems in developmental dyslexia: Under-recognized and under-treated. fournal of school psychology, 46(1), 1-21.

Biber, D. (1986). On the investigation of spoken/written differences. Studia Linguistica, 40(1), 1-21.

Bishop, D. (2009). Test for reception of grammar, version 2 (TROG-2). Svensk version. London, UK: Pearson Assessment.

Björnsson, C.-H. (1968). Läsbarhet. Stockholm: Liber.

Borin, L., Forsberg, M., Hammarstedt, M., Rosen, D., Schäfer, R., \& Schumacher, A. (2016). Sparv: Språkbanken's corpus annotation pipeline infrastructure. I The Sixth Swedish Language Technology Conference (SLTC), Umeå University, s. 17-18.

Chafe, W., \& Tannen, D. (1987). The relation between written and spoken language. Annual Review of Anthropology, 16(1), 383-407.

Connelly, V., Campbell, S., MacLean, M., \& Barnes, J. (2006). Contribution of lower order skills to the written composition of college students with and without dyslexia. Developmental neuropsychology, 29(1), 175-196.

Dockrell, J. (2009). Causes of delays and difficulties in the production of written text. I R. Beard, D. Myhill, J. Riley \& M. Nystrand (Red.), The SAGE Handbook of Writing Development (s. 487-505). London, England: SAGE.

Elwér, Å., Fridolfsson, I., Samuelsson, S., \& Wiklund, C. (2011). LäSt: Test i läsning och stavning. Stockholm: Hogrefe/Psykologiförlaget.

Frid, J., Johansson, V., Johansson, R., \& Wengelin, Å. (2014). Developing a keystroke logging program into a writing experiment environment. Writing Across Borders, 19-22 February 2014. Paris.

Graham, S., Gillespie, A., \& McKeown, D. (2013). Writing: Importance, development, and instruction. Reading and Writing, 26(1), 1-15. 


\section{Lexikala analyser av muntlig, tangentbordsskriven och dikterad text}

Graham, S., Harris, K., \& Hebert, M. (2011). Informing writing: The benefits of formative assessment. A report from Carnegie Corporation of New York. Carnegie Corporation of New York.

Hatcher, J., Snowling, M. J., \& Griffiths, Y. M. (2002). Cognitive assessment of dyslexic students in higher education. British journal of educational psychology, 72(1), 119-133.

Haug, K., \& Klein, P. (2018). The effect of speech-to-text technology on learning a writing strategy. Reading $\mathcal{E}$ Writing Quarterly, 34(1), 47-62.

Higgins, E. L., \& Raskind, M. H. (1995). Compensatory effectiveness of speech recognition on the written composition performance of postsecondary students with learning disabilities. Learning Disability Quarterly, 18(2), 159-174.

Järpsten, B., \& Taube, K. (2010). DLS: för skolår 4-6. Handledning. Hogrefe Psykologiförlaget.

Johansson, V. (2009). Developmental aspects of text production in writing and speech. Travaux de l'institut de Linguistique de Lund, 48 (Doktorsavhanding). Lund: Lunds universitet.

Limpo, T., \& Alves, R. A. (2013). Modeling writing development: Contribution of transcription and selfregulation to Portuguese students' text generation quality. Fournal of Educational Psychology, 105(2), 401.

MacArthur, C. A. (2009). Reflections on research on writing and technology for struggling writers. Learning Disabilities Research E Practice, 24(2), 93-103.

MacArthur, C.A., \& Cavalier,A. R. (2004). Dictation and speech recognition technology as test accommodations. Exceptional Children, 71(1), 43-58.

MacWhinney, B. (2014). The CHILDES project: Tools for analyzing talk,Volume II: The database. Psychology Press.

McCarthy, P. M., \& Jarvis, S. (2010). MTLD, vocd-D, and HD-D: A validation study of sophisticated approaches to lexical diversity assessment. Behavior research methods, 42(2), 381-392.

Nordenfors, M. (2011). Skriftspråksutveckling under högstadiet. Doktorsavhandling, Institutionen för svenska språket, Göteborgs universitet.

Olinghouse, N. G., \& Leaird, J. T. (2009). The relationship between measures of vocabulary and narrative writing quality in second-and fourth-grade students. Reading andWriting, 22(5), 545-565.

Perelmutter, B., McGregor, K. K., \& Gordon, K. R. (2017). Assistive technology interventions for adolescents and adults with learning disabilities: An evidence-based systematic review and meta-analysis. Computers $\mathcal{E}$ Education, 114, 139-163.

Quinlan, T. (2004). Speech recognition technology and students with writing difficulties: Improving fluency. fournal of Educational Psychology, 96(2), 337.

R Core Team (2017). R: A language and environment for statistical computing. R Foundation for Statistical Computing, Vienna, Austria. URL https://www.R-project.org/.

SBU. (2014). SBU. Dyslexi hos barn och ungdomar - tester och insatser. En systematisk litteraturöversikt. Stockholm: Statens beredning för medicinsk utvärdering (SBU). SBU-rapport nr. 225. ISBN 978-91-85413-66-9.

SFS 2018:1098 Lag om ändring $i$ skollagen (2010:800). Stockholm. Utbildningsdepartementet. Hämtad från: https://svenskforfattningssamling.se/sites/default/files/sfs/2018-06/SFS2018-1098.pdf

Šišková, Z. (2012). Lexical richness in EFL students' narratives. Language Studies Working Papers, 4, $26-36$.

Skar, G. B. (2013). Skrivbedömning och validitet: fallstudier av skrivbedömning $i$ svenskundervisning på gymnasiet. Doktorsavhandling, Institutionen för språkdidaktik, Stockholms universitet.

Skar, G. B., \& Berge, K. L. (2017). Elevers skrivförmåga och texters kvantitativa egenskaper. Skrivesenterets skriftserie 1. Nasjonalt senter for skriveopplæring og skriveforsking. Norges teknisk-naturvitenskapelige universitet, Fakultet for samfunns- og utdanningsvitenskap, Institutt for lærutdanning. Trondheim.

Skolverket. (2018). Elever med funktionsnedsättning. Hämtad från: https:/www.skolverket.se/for-dig-som-ar.../ elev-eller-foralder/smanavigation-elevers-rattigheter/elever-med-funktionsnedsattning.

Strömqvist, S. (2008). Språkutveckling i tal och skrift. I G. Oker-Blom, A. Westerholm, \& N. Österholm (Red.), Rum för språkutveckling. Utbildningsstyrelsen.

Stanovich, K. (1986). Matthew Effects in Reading: Some Consequences of Individual Differences in the Acquisition of Literacy. Reading Research Quarterly, 21(4), 360-407.

Sumner, E., Connelly, V., \& Barnett, A. L. (2016). The influence of spelling ability on vocabulary choices when writing for children with dyslexia. Fournal of learning disabilities, 49(3), 293-304.

TechSmith. (2018). Camtasia. (Version 3.1.6, Copyright 2006-2018) [Programvara] TechSmith Corporation.

Wengelin, A. (2002). Text production in adults with reading and writing difficulties. Gothenburg Monographs of Linguistics, 20.

Wengelin, Å. (2007). The word-level focus in text production by adults with reading and writing difficulties. I M. Torrance, L. van Waes, \& D. Galbraith (Red.), Studies in writing. Writing and cognition: Research and applications (s. 67-82). New York, US: Elsevier Science. 


\section{S. Kraft, F. Thurfjell, f. Rack, och Å. Wengelin}

Wengelin, Å., Bengtsson, L., \& Kraft, S. (2015). Dictation - to what extent could it facilitate writing for poor spellers? Poster presentation at the European Association for Research in Learning and Instruction, EARLI 2015: Towards a Reflective Society: Synergies between Learning, Teaching and Research. 25-29 aug, Limasol.

Wengelin, Å., Johansson, R., \& Johansson, V. (2014). Expressive writing in Swedish 15-year-olds with reading and writing difficulties. Writing development in children with hearing loss, dyslexia, or oral language problems: implications for assessment and instruction. I B. Arfé, J. Dockrell, \& V. Berninger (Red.), Writing development and instruction in children with hearing, speech and oral language difficulties (s. 242-269). Oxford University Press.

Wiig, E. H, Wayne A. S., \& Semel, E. (2003). Clinical Evaluation of Language Fundamentals, Svensk version. Pearson Assessment.

Wirdenäs, K., \& Holmberg, P. (2010). Skrivpedagogik i praktiken: Textkedjor, textsamtal och texttypologier i tre svensklärares klassrum. Språk E Stil, NF 20, 105-131.

Yu, G. (2009). Lexical diversity in writing and speaking task performances. Applied linguistics, 31(2), $236-259$. 